\title{
The role of English Corpus in Promoting the Research of English Teaching
}

\author{
Dapeng WANG \\ Teaching and Research Institute of Foreign Languages \\ Bohai University \\ Jinzhou,Liaoning, 121013 China
}

\begin{abstract}
The corpus is presented in a large number of real examples in the context of co-occurrence data or presented in a form conducive to attracting the attention of learners; strengthen the learner's memory, to help learners acquire the use of semantic and contextual summary of the law. English corpus has won an important seat in the English language study and lexicographers with its unique advantages, however, the potential role of English Corpus in English Teaching is worthy of our in-depth discussion. This paper analyzes the important role of English Corpus in English Teaching.
\end{abstract} effect

Keywords- English corpus, status quo and development trend,

\section{INTRODUCTION}

Corpus linguistics has over fifty years of history. Since the early 1960s, computerized corpus developed rapidly, many countries have set up their own corpus, such as the Brown Corpus, LOB corpus, LLC corpus, etc., it covers religion, fiction, entertainment, news, and many other genres. Since 1991, Collins and other publishing and Birmingham University joint construction of the "English Library" (BOE), its capacity has reached 580 million term times till 2007, and vocabulary is growing rapidly, its growth rate has reached by month and it has become corpus source Collins dictionary and grammar book. Domestic English corpus construction is relatively quite late, but it got remarkable achievements. The earliest English corpus was built in 2003, contains about 100 times more than one million words. Various types of corpus appeared in succession, covering a wide range, including "Chinese Language Majors Multilingual Corpus of English Corpus building and" construction, since 2008, which will become the most massive size of the corpus.

\section{ENGLISH CORPUS AND ITS RELATED CONCEPTS}

\section{A. Definition of Corpus}

Corpus (corpus) refers to the study of languages, with computer processing and storing material written and oral language. With the continuous improvement and popularization of the computer, create a special purpose corpus is no longer a fantasy, thirty years ago, it was thought to be impossible, but it is still a very popular thing. The
English Corpus is an English-based and object-established corpus.

\section{B. Classification of Corpus}

Concerning the classification of the corpus, I think, it is the same with all of the classification, according to the standard held by different studies for different purposes, the classification results may also differ. Because each of the views held different views, the classification will be very different. I'll summarize different literature in detail.

First, the corpus can be divided into general corpus and professional corpus. Universal Corpus (general corpus) generally refers to a wide range of collection, drawn from balanced large-scale corpus, and the number often reach hundreds of millions of words. Since the complex production, large organizations are generally produced, English National Corpus (BNC), the American National Corpus (ANC) is a typical representative. And compared with common corpus, professional use corpus (specialized corpus) refers to a particular area for a particular purpose of the collection of corpus research, such as domestic scholars Mr. Yang Huizhong, he made Shanghai Jiao tong University Science English Corpus (JDEST), which is world-renowned, Mr. Gui Shichun's self-built linguistic corpus, Mr. Cao Hejian's business English corpus, all of these belong to professional use.

Secondly, in terms of time dimension, the corpus can be split into synchronic research and diachronic research which can be divided into synchronic corpus and diachronic corpus. Synchronic corpus refers the lateral corpus in a time point, diachronic corpus generally refers to a longitudinal study of a particular issue. If textbook did not have definition of the research and selection, but collect all of the corpus since the founding of the nation, the corpus made will be a diachronic corpus of ancient Chinese college English teaching.

\section{THE STATUS ANALYSIS OF CORPUS}

\section{A. The development process of Corpus}

From the induction and analysis of nearly a decade of development carried out in English corpus, we can see that, there is growing emphasis on research in the field, real analytical content of Corpus and large amounts of data are so convenient and efficient that they attract people to use them, especially in recent years, the teaching of English corpus used in research papers is increasing in all aspects of English 
teaching, and it showed a clearly rising trend. In the past two years, the application of corpus has a broader range and has more level extensive level.

\section{B. The study of application teaching}

First, the corpus can be directly applied to English teaching, for example, to explain the corpus of knowledge, to explain and explore ways and means of how to use the corpus data for teaching, etc., all of these belong to the corpus of immediacy use. Secondly, through the compilation of dictionaries, the reference of grammar materials, the use of computer technology, software development and other multimedia corpus, indirectly use instructional design corpus. Professor He An ping has analyzed and summed up the reality of teaching English corpus, it will be reflected in the following three aspects: First, in conjunction with teaching resources, that is to say, we need to put teaching materials into the corpus of information as the focus when writing the outline of textbooks; Second, in conjunction with the classroom teaching, that is to say, when selecting reading material, we need to use corpus resources as learning vocabulary and grammar; third is the combination of research and teaching, although China's current English Corpus reflected in the field of teaching and research, it still be neglected on construction of teaching resources, so for the construction of English teaching resources research, English Corpus still has room for development and utilization value.

\section{THE DEVELOPMENT TRENDS OF ENGLISH CORPUS}

\section{A. English Corpus capacity will be further enlarged}

From the first machine-readable electronic corpus-Brown Corpus appeared in the United States, many different types of corpora have been created, and the capacity of the corpus gradually enlarged. last century in the early 1960s, Brown corpus created a million words times, at that time it was a big corpus, but in 1995 the British National Corpus was completed, its capacity has reached 100 million term times, English library has increased from 6 million to 200 million term times extended term times, allegedly in 1997 the Corpus capacity has more than 300 million words times, and is constantly expanding. It is foreseeable that the corpus growing trend will continue, will further increase the capacity of the corpus.

\section{B. Research and preparation of the potential ESP large corpus}

In the English corpus linguistics, like COBUILD corpus, so large and comprehensive corpus affect the British National Corpus and the International Corpus of English is very large, in contrast, appeared to be very thin corpus special purpose, existing for research lexicography, special purpose corpus language acquisition, English language learners and technology and other aspects, such as child language information exchange system databases, translation English Corpus, AHI corpus and JDEST corpus, etc., can not meet the actual demand. In efforts to build large, integrated corpus while to build more, with professional and relatively small ESP corpus will be a big trend.

\section{THE ROLE OF ENGLISH CORPUS IN PROMOTING THE TEACHING OF ENGLISH}

\section{A. To promote the teaching of English speech}

In the past, during the teaching of listening and speaking, almost all of us have heard are standard London or authentic American English, but in reality, because the English language users are different in age, region, race and other differences, there are differences in language we heard and we contacted in the learning process, and these differences lead to some obstacles in listening and speaking, therefore, it has been proposed to increase the variety of variants and inputs. Spoken English Corpus is a special corpus, it is actually one of the world's English accent variants encyclopedia, when teachers are learning various aspects of variants, you can verify phonetics theory through corpus to explain and demonstrate better, in addition, teachers can choose relevant content of accent corpus as a model material by providing real English voice features to enhance the learner's self-confidence of their own pronunciation.

\section{B. To cultivate students' self-learning ability in English}

the current English teaching, although advocates students-centered with teachers helping, giving the initiative to improve the students' enthusiasm, changing the "spoon-fed" or "chalk and talk" teaching methods, but all the organizations and activities are controlled by teachers who are ready to present knowledge to the students. Using Corpus can allow students to use keyword search to find a word or sentence structures that appear in the corpus, let students study these examples, from his own induction, find out the language law, which not only encourages students to reinforce each other's cooperation and jointly explore and identify problems, but also enable students to become truly independent learners, to help students form their own ability to learn languages, and shift from "learn to" can learn ".

\section{Analysis of students' language errors}

Error analysis has been prevalent in the sixties and seventies in the last century. The aim is to find the cause of why students utter the wrong speech and language learning rules. But before the appearance of the corpus, teachers can only obtain comprehensive verbal errors from a fragmented system of students. Teachers can not see the whole picture of students' errors. Corpus can help teachers discover and identify a word or sentence structure appearing in the corpus, let students studies these examples, from his own induction, find out the language law. "Corpus can help teachers establish a new autonomous language learning model, teachers can form a learner needs analysis in the analysis of the characteristics of the individual learner, according to this analysis, select the appropriate language-learning materials for the students in the learning corpus according to the characteristics of his own 'custom' language learning mode, and then let students independently learn languages, and finally assess their learning. Autonomous learning and assessments and timely feedback to the learner and learner corpora make this self-learning process more accurate to the 
students' learning needs, reflects the learner-centered thinking to help students form their own ability to learn languages.

Teaching Corpus contributes to research and study of vocabulary, in the era of rapid development of information technology; to put the corpus into English vocabulary teaching is a wise move. English Corpus, provides check, data analysis including the collocation of examples based on web platform for learners, it provides a new utility for the learner's vocabulary study. While in the process of teaching vocabulary, it allows students to fully express their learning initiative, enthusiasm and develop good self-study habits, it also helps to develop a comprehensive quality talent.

\section{The role of corpus in promoting the post position word of intransitive adverb}

Some students are usually headache on what adverb or adverbial should follow with intransitive verb. Teachers search through a large corpus of examples so that students can more easily grasp the authentic expressions. Such as by observing the following corpus, students can easily find the word behave normally followed by which adverb or adverbial.

That corpus has an important effect to language teaching and research is an indisputable fact, specific to the field of research and practice of English vocabulary teaching, it also plays a significant role. Corpus' role in vocabulary teaching is also reflected in the distinction between the words which can provide information stylistic characteristics (oral / written, formal / informal, etc.) as well as English vocabulary polysemy, the observation of old words having new meaning and its exploration, thereby grasp the basic laws of English words change with the general trend of changes in characteristics and other aspects of language experience. With a more extensive corpus research and application, we will be more comprehensively and profoundly understanding it and use it to serve the scientific language research and teaching practice and exploration in a wider range of vocabulary teaching, and so many other areas of research and practice get greater returns.

\section{E. Corpus can improve the evaluation system of English proficiency test}

English proficiency test is an indispensable component of English teaching; network-based personalized English Corpus English test can be fully integrated with the requirements of different stages to improve the existing evaluation system of English institutions. English evaluation system, including the use of multi-segmented evaluation method for learning English in several aspects of evaluation, including listening, speaking, reading, writing, testing the ability of translation. If you could create a learning corpus files, the level of students' self-assessment test can combined with each other, can be more convenient and effective to feedback students' real learning situation.

\section{F. English corpus can facilitate students' learning motivation}

Because there are a lot of language materials with authenticity and timeliness of English corpus, so if you use the English teaching corpus, you can improve students' language awareness and learning ability, because it can not only reflect the objective of the corpus language, but also demonstrate the real use of language. Furthermore, since the corpus are used in a variety of storage of the electronic version available for teachers and students to repeat an unlimited number of searches, it has autonomy and openness characteristics, thus it contributes to the students' willingness to learn, such a learning approach helps inspire students to learn English initiatively.

\section{CONCLUSIONS}

As we can see from above discussion, promoting role of the corpus on college English teaching is obvious. Take the corpus into English teaching, can make full use of the supervisory role of teachers, and can guide students' language awareness and self-learning ability, so the effect of language teaching is significantly enhanced. More importantly, it makes the original theoretical stages of language teaching ideas into reality. The application of corpus technology in English teaching will profoundly change our language teaching ideas, learning English as well as English teaching mode. Foreign language teachers should master the language corpus, adhere to student-centered, and make use of authentic language teaching materials, so that the corpus tool can better serve foreign language teaching service in the actual teaching.

\section{REFERENCES}

[1] Zhang Jinfu. study based on contemporary American English Corpus of Chinese students' vocabulary proficiency in English composition[D]. Shanghai International Studies University, 2012.

[2] Jiaobin Kai. Implications for English Corpus of English teaching in China [J]. Xuchang University,2006,06:86-88.

[3] Liu Shifang. Promote Corpus of English vocabulary teaching [J]. Anhui University of Technology (Social Science Edition),2007,04:65-67.

[4] Shi Xia. Promote English Corpus of English Teaching in China [J]. Technological information,2010,33:247-248.

[5] Zhang Huiping. based on the concept of Chinese learners of English Corpus migration research [D]. Northeast Normal University, 2013.

[6] Anyuanyuan. On the role of English Corpus of English vocabulary teaching $[\mathrm{J}]$. Jilin Province Economic Management Personnel Institute,2013,05:93-95. 